\title{
Repensando as habilidades de leitura no ensino superior sob a ótica da Psicolinguística Experimental
}

\author{
Joana Angélica de SOUZA ${ }^{1}$ \\ Eduardo KENEDY
}

\footnotetext{
${ }^{1}$ Universidade Federal Fluminense (UFF), joanasouza@id.uff.br, orcid.org/oooo-00023652-1540.

${ }^{2}$ Universidade Federal Fluminense (UFF) | Conselho Nacional de Desenvolvimento Científico e Tecnológico (CNPq), eduardokenedy@id.uff.br, orcid.org/0000-0003-45310689.
} 
RESUMO As perspectivas do acesso ao ensino superior no Brasil são otimistas. Em relação há algumas décadas, o número de jovens com acesso a universidades públicas e privadas aumentou consideravelmente. Segundo dados do IBGE, em 2004, a parcela de jovens de 18 a 24 anos nas faculdades era de $32,9 \%$ e em 2014 passou para 58,5\% (IBGE, 2015). No mesmo ano de 2014, a Universidade Católica de Brasília do Distrito Federal verificou que 50\% dos universitários do DF são analfabetos funcionais, enquanto pesquisa do IBGE identificou que no Brasil esse número é de 38\% (KENEDY, 2016). Paralelamente, o Indicador de Alfabetismo Funcional (INAF) de 2016 aferiu que, do total da população no nível superior ou mais, $4 \%$ está classificado como tendo um nível rudimentar de leitura, $32 \%$ se encontra no nível elementar e $42 \%$ está no nível intermediário, totalizando $78 \%$ de pessoas não proficientes em leitura dentre os universitários (AÇÃO EDUCATIVA, 2016). Vale ressaltar que entendemos analfabetismo funcional como a condição na qual o indivíduo é incapaz de produzir e atribuir significado a textos escritos nos mais diferentes contextos em sua vida cotidiana familiar, social e de trabalho (CABRAL, 2003). A partir da observação desses dados, é imperativo que para um aproveitamento satisfatório de um curso superior, o indivíduo seja plenamente 
letrado. Sendo assim, tomamos como base teórica os estudos de psicolinguística sobre leitura e aplicamos um experimento de leitura - Teste de Cloze - a alunos ingressantes no curso de Letras da Universidade Federal Fluminense, cuja variável dependente foi $\mathrm{o}$ score no teste e as variáveis independentes foram o grupo (cotistas/não cotistas) e o tipo de item (palavra de conteúdo/palavra funcional), nossas hipóteses foram de que os cotistas apresentariam um resultado inferior no teste de Cloze e de que as palavras funcionais apresentariam menos dificuldade aos participantes por representarem níveis mais básicos do processamento do texto escrito.

ABSTRACT The perspectives of access to higher education in Brazil are optimistic. In relation to some decades ago, the number of young people with access to public and private universities increased considerably. According to IBGE data, in 2004, the proportion of young people aged from 18 to 24 in colleges was $32.9 \%$ and in 2014 it was $58.5 \%$ (IBGE, 2015). In the same year, the Catholic University of Brasilia of the Federal District found that 50\% of university students in the Federal District are functional illiterates, while the IBGE survey found that in Brazil this proportion is $38 \%$ (KENEDY, 2016). At the same time, the Functional Literacy Indicator (INAF) of 2016 
verified that from the total population in the university or with a higher level, $4 \%$ is classified as having a rudimentary level of reading, 32\% is at the elementary level and $42 \%$ is at the intermediary level, totaling $78 \%$ of people who are not proficient in reading among university students (AÇÃO EDUCATIVA, 2016). It is worth noting that we understand functional illiteracyastheconditioninwhichtheindividual is incapable of producing and understanding written texts in the most different contexts of our daily family, social and work life (CABRAL, 2003). From the observation of these data, it is imperative that for a satisfactory achievement of the higher course, the individual be fully literate. Thus, we take as theoretical basis the studies of psycholinguistics on reading and apply a reading experiment - Cloze test - to students entering the course of Literature and Language of the Federal University Fluminense, which dependent variable was the score in the test and the independent variables were the entrance in university (affirmative action/wide competition) and the type of item (content word/functional word), our hypotheses were that those who entered university by affirmative action would have a lower result in the Cloze test and that the functional words would present less difficulty to the participants because they represent basic levels of written text processing. 
PALAVRAS-CHAVE leitura. letramento. analfabetismo funcional. psicolinguística.

KEYWORDS reading. literacy. functional illiteracy. Psycholinguistics. 


\section{Introdução}

Nas últimas décadas, o número de jovens com acesso a universidades públicas e privadas vem aumentando consideravelmente. Segundo dados do IBGE, em 2004, a parcela de jovens de 18 a 24 anos nas faculdades era de 32,9\% e em 2014 passou para $58,5 \%$ (IBGE, 2015).

Isso, naturalmente, se reflete em um maior acesso a bens culturais, aumento da qualidade de vida, poder aquisitivo e faz parte do processo de desenvolvimento dos países. Podemos pensar a princípio, a partir desse cenário, que quanto mais jovens com acesso ao ensino superior, menores os índices de analfabetismo funcional. No entanto, o que se vê é um número ainda muito elevado de analfabetos funcionais dentro das universidades.

Em 2014, a Universidade Católica de Brasília do Distrito Federal verificou que 50\% dos universitários do Distrito Federal são analfabetos funcionais, enquanto pesquisa do IBGE identificou que no Brasil esse índice é de 38\% (KENEDY, 2016). A explicação para isso naturalmente está nas deficiências da educação básica, que faz com que um indivíduo consiga passar por todas as suas etapas, desde a alfabetização até o ensino médio, sem aprender a ler de forma proficiente.

Vale ressaltar que entendemos analfabetismo funcional como a condição na qual o indivíduo é incapaz de produzir e atribuir sentido a textos escritos nos mais diferentes contextos em sua vida cotidiana familiar, social e de trabalho (SCLIAR-CABRAL, 2003). Em outras palavras, o analfabeto funcional consegue decodificar o material linguístico de um texto, mas é incapaz de gerar representações de sentido para textos em registro mais formal e com estrutura complexa. Nesse sentido, ser letrado não significa saber representar ortograficamente a língua falada na comunidade do indivíduo, mas ter autonomia para entender e criar textos em diferentes gêneros textuais e em diferentes graus de formalidade e registros. 
Os dados do Indicador de Alfabetismo Funcional (INAF) de 2016 também corroboram com os resultados encontrados pelo IBGE, indicando que uma significativa parcela da população chega à educação superior sem alcançar a proficiência em leitura. Do total da população no nível superior ou mais, $4 \%$ está classificado como tendo um nível rudimentar de leitura, $32 \%$ se encontra no nível elementar e $42 \%$ está no nível intermediário, totalizando $78 \%$ de pessoas não proficientes em leitura dentre os universitários (AÇÃO EDUCATIVA, 2016).

Cabe destacar que no contexto educacional há diversas variáveis que concorrem para o mau desempenho dos alunos em atividades de leitura e uma delas é a socioeconômica (MENEZES-FILHO, 2007). No ensino superior, o ingresso pelo sistema de ações afirmativas por alunos oriundos de escola pública é um dos fatores que podem nos ajudar a observar as diferenças nos resultados obtidos por alunos cujo background familiar remete a uma condição de fragilidade social e econômica.

O objetivo das ações afirmativas é, sobretudo, ajudar a reparar a exclusão social ocorrida no passado ou no presente. Tal reparação, no entanto, inclui também repensar e elaborar programas para que o grupo que eventualmente não tenha desenvolvido plenamente suas habilidades de leitura ao longo da educação básica possa no ensino superior ter condições similares à dos grupos privilegiados socialmente.

Sendo assim, participaram do presente estudo alunos de licenciatura do curso de Letras e tal escolha se deu em função do fato de que repensar a competência leitora no contexto da formação de professores em nível superior é também um esforço no sentido de melhorar a qualidade da educação básica das gerações futuras. 


\section{Revisão da Literatura}

$\mathrm{O}$ ato de ler pode parecer natural e simples à primeira vista, mas do ponto de vista cognitivo, é uma atividade extremamente complexa e recente na história da humanidade. Para fins teóricos, subdivide-se o processamento da leitura nas seguintes etapas: a leitura se inicia com (a) o input visual que, com o uso imediato da fonologia, leva à identificação da palavra, que, por sua vez, (b) gera informações semânticas, restritas pelo contexto, para cada palavra. As palavras são imediatamente (c) integradas sintaticamente a uma frase e (d) semanticamente a uma proposição. À medida que as frases são lidas, (e) uma representação integrada do textoé desenvolvida, consistindo de proposições interconectadas. Finalmente, com o objetivo de estabelecer uma compreensão razoavelmente específica de um texto, (f) são estabelecidas inferências que compõem um modelo referencial coerente do que está sendo lido (PERFETTI, 2001, p.31).

No entanto, o ato de ler não se restringe a uma sucessão de etapas cronologicamente marcadas, que se inicia na primeira linha e se encerra no ponto final. Como indicamos acima, essa divisão em estágios se dá pela necessidade teórica de entender o processamento. A leitura, antes de qualquer coisa, está profundamente vinculada às experiências passadas doindivíduo ea elas se incorpora, reverberando por sua vivência posterior. É preciso que tenhamos em mente o que explicitou Scliar-Cabral (1986):

Cumpre assinalar que a enumeração destes subprocessos não significa que eles operem de baixo para cima unidirecionalmente. Os processos perceptuais e cognitivos atuam numa corrente contínua e isócrona, ou, então, com diferenças mínimas em milissegundos, de forma que cada saída ou produto de um subprocessamento é influenciado por outros subcomponentes. (SCLIAR-CABRAL, 1986, p. 8) 
Cabe destacar que entendemos leitura como o processamento cognitivo de textos verbais escritos de maneira incrementacional, adotando o modelo teórico de processamento de frases incrementacional-interativo (CRAIN \& STEEDMAN, 1984; ALTMANN \& STEEDMAN, 1988), que prevê uma interação fraca entre os módulos sintático e semântico/referencial.

Dizer que o processamento ocorre de maneira incremental significa dizer que ocorre palavra a palavra, ou seja, não esperamos o final de uma sentença para criar uma interpretação, ao longo do curso da leitura já criamos representações que nortearão o sentido do que virá a seguir no texto, conforme explicitado por Altmann e Steedman (1988). Com a progressão da leitura, nosso processador mental vai acumulando novos itens lexicais que carregam informações sintáticas e semânticas, ativando ou inibindo novos caminhos que levarão à interpretação do que está sendo lido.

Acapacidade deleréumaforma específica dacapacidade damente de transformar representações de entrada (input) em representações de saída (output), ou seja, transformar um determinado estímulo visual em representação fonológica na forma de informação a ser utilizada pelo resto do sistema cognitivo.

É importante ressaltar que ainda que o objetivo do ato de ler seja a compreensão, não se pode dizer que os processos de ler e compreender se identificam, pois a decodificação do material escrito e transformação em matéria fonológica é parte imprescindível do ato de ler. Nas palavras de Morais, "a leitura não atinge seu objetivo sem compreensão, todavia os processos específicos da leitura não são processos de compreensão, mas que levam à compreensão" (MORAIS, 1996, p. 114).

Como já dito, a leitura é uma atividade de alta complexidade, que envolve diversos aspectos da cognição humana, tais como a linguagem, a memória, o pensamento, a inteligência e a percepção 
(ADAMS, 1999; GARROD, DANEMAN, 2003).É importante pontuar também que na leitura satisfatória de um texto estão envolvidos quatroprocessos básicos: decodificação, compreensão,interpretação e retenção. (SCLIAR-CABRAL, 1986)

Dentro desses quatro processos, existem diversos subprocessos, a seguir explicitados:

Os subprocessos que constituem o ato da leitura (considerando textos de prosa) vão desde as fixações precedidas e seguidas dos movimentos em sacadas, reconhecimento da palavra, fatiamento de unidades básicas de significação na sentença, captação das funções das entidades que as compõem e de seu relacionamento, apropriação do sentido adequado das palavras ao contexto, com eliminação de outros sentidos possíveis (polissêmicos ou ambíguos), relacionamento das significações entre as sentenças, utilização de todos os elementos correferenciais $\mathrm{e}$, finalmente, as inferências que darão unidade ao texto em exame. Resumidamente, poderemos dizer que há quatro etapas decisivas no processo da leitura: decodificação, compreensão, interpretação e retenção. (SCLIAR-CABRAL, 1986, p. 8)

Vale ressaltar que em um indivíduo adulto, que já automatizou de forma fluente e adequada o processo da leitura, esses subprocessos não necessariamente ocorrem de forma linear, um após o outro e unidirecionalmente, o que faz com que a leitura não seja caracterizada como um processo bottom-up ou ascendente (STERNBERG, 2012).

O modelo bottom-up de processamento da leitura prevê que o indivíduo parte da decodificação das letras em sons, para então compor sílabas que possibilitarão a identificação de palavras, que serão processadas e formarão frases, para então alcançar o sentido global do texto (KATO, 1999). Esse modelo, além de pecar ao deixar de considerar as distinções entre letra e grafema e ao deixar de 
diferençar som e fonema, tampouco é capaz de garantir que, após a realização das primeiras etapas mais estruturais de decodificação, alguma compreensão satisfatória será alcançada no decorrer da leitura.

Evidentemente, há leitores que permanecem, ao longo da sua experiência de vida, realizando apenas uma leitura mecânica e não conseguem ultrapassar o nível da decodificação (JERÔNIMO, 2012, p. 85).

Existe também um modelo que se opõe ao modelo ascendente e é chamado de top-down ou descendente. Esse modelo segue o pressuposto de que a leitura é um processo pelo qual o leitor parte de seu conhecimento pragmático, discursivo e semântico para selecionar as pistas linguísticas a serem decodificadas. Isso significa que as informações dos níveis mais elevados do processamento influenciam as informações dos níveis mais básicos.

De acordo com Kato (1999), no processamento top-down, o leitor apreende as ideias gerais e principais do texto, lê de forma mais rápida, porém menos precisa, podendo fazer excessos de adivinhações. Nesse tipo de processamento, o conhecimento do leitor tem mais peso na leitura do que a informação efetivamente dada pelo texto.

Dados obtidos com o uso de rastreamento ocular (CARPENTER, JUST, 1983) indicam que durante o curso da leitura $62 \%$ das palavras funcionais (preposições, artigos, conjunções) não são fixadas, contra apenas 18\% das palavras de conteúdo (verbos e nomes). Embora não se possadizerque afixação e sua duração correspondam precisamente ao tempo de processamento empregado naquela palavra, é possível realizar inferências a respeito do custo de processamento a partir desses dados (HAYHOE, 2004), também sugerindo um tipo de processamento mais próximo do top-down. 
Foucambert (1994) sintetiza os dois modelos da seguinte forma:

- o modelo ascendente (bottom up), que parte das letras para as sílabas, as palavras, as frases... e funciona com base na decodificação, indo do simples ao complexo; - o modelo descendente (top down), que parte do conjunto (da Gestalt) e caminha do sentido para os elementos que o expressam. (FOUCAMBERT, 1994, p. 53)

O terceiro e último modelo é chamado de interativo e integra os dois modelos acima abordados. Para o modelo interativo, durante a atividade de leitura ocorre uma sucessão de etapas de recuperação fonológica, morfossintática, semântica, discursiva e pragmática. Tais etapas muitas vezes ocorrem simultaneamente e fazem com que ler seja um fenômeno complexo do ponto de vista cognitivo e profundamente relacionado às práticas sociais e culturais do indivíduo.

O processamento do texto, isto é, o agrupamento e transformação de unidades de um nível (por exemplo, letras) em unidades significativas de outro nível (por exemplo, palavras) se faz tanto a partir do conhecimento prévio e das expectativas e objetivos do leitor (chama-se esse tipo de processamento descendente ou de-cima-para-baixo) quanto a partir de elementos formais do texto à medida que o leitor os vai percebendo (chama-se esse tipo de processamento ascendente, ou de-baixo-para-cima). (KLEIMAN, 2007, p. 55)

De maneira independente aos estudos citados, Maia (2018) realizou uma pesquisa experimental on-line com estudantes de nível superior e fundamental do estado do Rio de Janeiro. Num estudo de rastreamento ocular original e inédito no Brasil, Maia identificou que, ao atingirem o último ano do ensino fundamental, os alunos daquele segmento escolar ainda procedem a uma leitura 
linear, não estruturante, da direta para a esquerda, independente da hierarquização entre orações matriz e subordinada que possa caracterizar um período específico. Tal comportamento contrasta com o de um leitor mais maduro, conforme aferido pelo autor com estudantes de nível superior. Esse leitor, tal como flagrado no experimento, realiza uma leitura estruturante, que evidencia a busca por relações hierárquicas entre os constituintes que compõem o período. Isso quer dizer que, enquanto o leitor de nível fundamental fixava seu olhar preferencialmente nos constituintes iniciais do período, fosse esse uma oração matriz ou uma subordinada, o leitor universitário mostrava mais flexibilidade durante seus movimentos sacádicos, à procura de informações estruturantes quando o período se iniciava por uma oração subordinada. Os achados de Maia são relevantes porque indicam a relevância de considerar os processos (on-line) de leitura no curso da formação de leitores, e não somente os produtos (off-line) da leitura.

A leitura é a base da educação, pois o desenvolvimento em todas as áreas do conhecimento depende de proficiência no ato de ler. Assim, pensar sobre o desenvolvimento de habilidades de leitura na universidade pode parecer desnecessário em um primeiro momento, pois se espera que os problemas de competência leitora tenham se resolvido ao longo dos ciclos anteriores de educação. No entanto, após a verificação dos dados alarmantes já aqui referidos, nosso objetivo é demonstrar que também é preciso voltar nosso olhar para as questões de leitura na universidade, sobretudo no contexto de formação dos futuros professores que trabalharão na educação básica. 


\section{Metodologia}

\subsection{Objetivos}

Definimos para este estudo os seguintes objetivos:

- Avaliar as habilidades de leitura dos ingressantes no ensino superior, especificamente no curso de Letras da Universidade Federal Fluminense;

- Descrever em quais níveis de processamento linguístico se situam os problemas de leitura identificados.

- Posteriormente, acompanhar o desenvolvimento das habilidades de leitura dos participantes ao longo da graduação a fim de identificar o papel da universidade enquanto agência de desenvolvimento da competência leitora.

\subsection{Técnica}

A técnica escolhida para o experimento foi o Teste de Cloze (TAYLOR, 1953), que consiste em um modelo de testagem de compreensão de textos off-line (não cronométrico), usado na Linguística Aplicada e na Psicologia Cognitiva, criado para medironível de compreensibilidade de textos por parte do leitor e fundamentado na Teoria da Informação e na ideia de amostra aleatória (ADELBERG, RAZEK, 1984). "Logo se descobriu que o Cloze não media apenas a inteligibilidade do texto, mas era também um instrumento válido e confiável para medir a proficiência de leitura; a variação de acertos no teste discrimina fidedignamente o leitor fluente do leitor fraco" (LEFFA, 1996, p. 70).

O teste consiste em retirar palavras de um texto aleatoriamente e substituí-las por lacunas a serem preenchidas pelos participantes. Assim, quanto mais lacunas forem preenchidas corretamente, de acordo com critérios de coesão e coerência, maior será o score do participante no que se refere à compreensão. 
A compreensão de um texto que apresenta lacunas a serem preenchidas depende necessariamente da elaboração de hipóteses, etapa essencial do ato de ler, conforme indicado por Perfetti (2001). Paralelamente, na escala de proficiência em leitura do Relatório Nacional PISA (em inglês: Programme for International Student Assessment) 2012, o nível mais elevado exige "que o leitor realize múltiplas inferências, comparações e contrastes (...), integração de informações de um ou mais textos (...), lide com ideias desconhecidas (...) e formule hipóteses sobre um texto complexo relativo a um tema desconhecido" (INEP, 2012, p. 42).

Sendo assim, o teste de Cloze traz a possibilidade de avaliar a proficiência em leitura, pois trabalha precisamente com a criação de hipóteses, ao assumir um modelo top-down de leitura. Para realizar o teste, o participante precisa reconstruir a mensagem do texto, que é capaz de atribuir um significado global ao que lê.

\subsection{Hipóteses}

A primeira hipótese do presente experimento é a de que fatores socioeconômicos influenciam nas habilidades de leitura dos participantes e se deriva da ideia de que não apenas critérios educacionais convergem para o mau desempenho dos alunos (MENEZES-FILHO, 2007).

Já a segunda hipótese é a de que no preenchimento das lacunas do teste de Cloze haverá diferenças, no sentido de maior ou menor índice de preenchimentos corretos, entre as palavras de conteúdo (substantivos, adjetivos, verbos) e as palavras funcionais (preposições, artigos, conjunções), seguindo os resultados obtidos com a técnica de rastreamento ocular (CARPENTER, JUST, 1983). 


\subsection{Previsões}

As previsões do presente experimento são as de que os ingressantes pelo sistema de ações afirmativas apresentarão um desempenho inferior ao dos alunos ingressantes por ampla concorrência, pois acreditamos que a educação básica privada, apesar dos graves problemas na formação de seus alunos, ainda reúne um público com menos fragilidade socioeconômica. Além disso, prevê-se que as palavras de natureza funcional apresentarão maior índice de acertos entre ambos os grupos, por contraste às palavras de cunho referencial, uma vez que aquelas podem ser deduzidas pelo contexto imediato da construção sintática, independente da coerência global do texto.

\subsection{Variáveis}

As variáveis independentes foram o grupo (ingressantes por ação afirmativa/ingressantes por ampla concorrência) e o tipo de item (palavra de conteúdo/palavra funcional). A variável dependente foi o score no Teste de Cloze.

\subsection{Condições}

A partir das variáveis acima, temos quatro condições experimentais. A saber: 1) Desempenho dos ingressantes pelo sistema de ações afirmativas nas palavras de conteúdo; 2) Desempenho dos ingressantes pelo sistema de ações afirmativas nas palavras funcionais;3) Desempenho dos ingressantes por ampla concorrência nas palavras de conteúdo; 4) Desempenho dos ingressantes por ampla concorrência nas palavras funcionais. 
Quadro 1: Plano Fatorial do Experimento (2x 2)

\begin{tabular}{|l|l|l|l|l|}
\hline \multirow{2}{*}{} & \multicolumn{2}{|c|}{ Cotistas (AA) } & \multicolumn{2}{c|}{ Não Cotistas (AC) } \\
\cline { 2 - 5 } & $\begin{array}{l}\text { Palavras de } \\
\text { Conteúdo } \\
\text { (AA) }\end{array}$ & $\begin{array}{l}\text { Palavras } \\
\text { Referenciais } \\
\text { (PR) }\end{array}$ & $\begin{array}{l}\text { Palavras de } \\
\text { Conteúdo (AA) }\end{array}$ & $\begin{array}{l}\text { Palavras } \\
\text { Referenciais } \\
\text { (PR) }\end{array}$ \\
\hline $\begin{array}{l}\text { Score } \text { no } \\
\text { Teste (ST) }\end{array}$ & ST AA AA* $^{*}$ & ST AA PR* & ST AC AA* & ST AC PR* $^{*}$ \\
\hline
\end{tabular}

* Medidas das variáveis dependentes a serem preenchidas com os resultados do experimento

\subsection{Material}

Quanto ao material, usamos um texto de divulgação científica com tema científico, mas linguagem acessível ao público universitário, intitulado "Inteligência Artificial: UFF cria soluções inovadoras para a sociedade" (que pode ser acessado no endereço http://www. uff.br/?q=noticias/19-09-2017/inteligencia-artificial-uff-criasolucoes-inovadoras-para-sociedade), retirado do site da própria universidade dos participantes, e um questionário que tinha como função verificar os hábitos de leitura e o contexto socioeconômico, ambos impressos em papel A4.

\subsection{Participantes}

O questionário foi aplicado a um total de 22 alunos que estavam inscritos na disciplina de Português I no segundo semestre de 2017, ou seja, alunos que haviam acabado de ingressar no curso de graduação de Letras na Universidade Federal Fluminense. Dois desses participantes foram eliminados - um era aluno de Filosofia e estava cursando Português I como ouvinte e o outro deixou muitas lacunas em branco - e analisamos o resultado de 20 participantes. A distribuição foi within-subjects, ou seja, todos os participantes estavam expostos às mesmas condições experimentais. 


\section{Resultados e Discussão}

Antes de apresentarmos os resultados do experimento, vamos exemplificarcomosedeuacorreçãodoTestedeCloze. Primeiramente, não seguimos um gabarito para corrigir as respostas dadas pelos alunos, mas analisamos se haveria uma interpretação possível vinculada à escolha das palavras, como nos exemplos a seguir.

Figura 1: Exemplo de correção 1

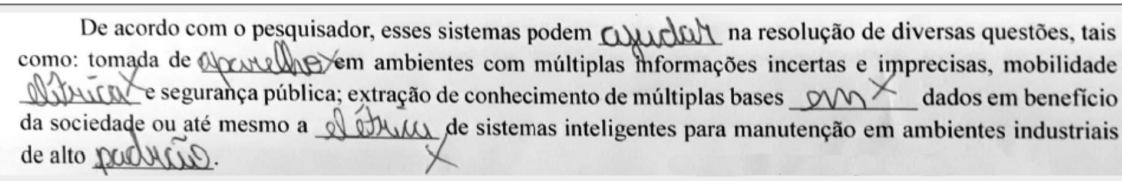

Figura 2: Exemplo de correção 2

De acordo com o pesquisador, esses sistemas podem AuXILIAR na resoluçao de diversas questões, tais como: tomada de $D E C I S \tilde{A} O$ em ambientes com múltiplas informações incertas e imprecisas, mobilidade URBANA e segurança pública; extração de conhecimento de múltiplas bases $D \in U$ dados em benefício da sociedade ou até mesmo a PROOUCÁ de sistemas inteligentes para manutenção em ambientes industriais de alto NÍvel.

O trecho original correspondente aos exemplos era "De acordo com o pesquisador, esses sistemas podem ajudar na resolução de diversas questões, tais como: tomada de decisão em ambientes com múltiplas informações incertas e imprecisas, mobilidade urbana e segurança pública; extração de conhecimento de múltiplas bases de dados em benefício da sociedade ou até mesmo a criação de sistemas inteligentes para manutenção em ambientes industriais de alto risco".

No exemplo 1, temos algumas palavras que foram consideradas erradas porque não havia uma leitura possível que justificasse o uso de "tomada de aparelho", "mobilidade elétrica", "bases em dados" e “elétrica de sistemas inteligentes”. Já no exemplo 2, todas as palavras foram consideradas corretas, ainda que não estivessem iguais ao 
texto original. "Auxiliar" e "ajudar" são sinônimos, por isso o item foi considerado correto, assim como "criação" e "produção". Já "nível" não é sinônimo de "risco", no entanto, é coerente pensar em sistemas de inteligência artificial que possam contribuir em ambientes industriais de alto nível, portanto, o item também foi considerado correto.

Ainda no exemplo acima, temos cinco lacunas que correspondem a palavras de conteúdo e uma que corresponde a palavra funcional ("de"). No total das 45 lacunas do texto (as duas primeiras foram desprezadas na correção porque os estudantes estavam aprendendo a tarefa), foram 31 lacunas referentes a palavras de conteúdo e 14 referentes a itens funcionais. As análises foram feitas com base em percentuais, pois onúmero de palavras paracada condiçãoédiferente, devido à aleatoriedade nas lacunas típica do teste de Cloze. Os vinte participantes selecionados para o experimento foram divididos em dois grupos, sendo nove participantes ingressantes pelo sistema de ações afirmativas (AA) e onze participantes ingressantes por ampla concorrência (AC). Todos os participantes informaram que gostam de ler, dezessete participantes informaram que leem pelo menos cinco livros por ano e três informaram que leem até cinco livros por ano.

O teste Qui-Quadrado, realizado com o Action, não mostrou interação entre as variáveis. Quanto à primeira previsão, relativa ao grupo, a hipótese nula foi rejeitada $(\mathrm{p}<.05)$. Já quanto à segunda previsão, a hipótese nula não foi rejeitada ( $\mathrm{p}>.05$ ), conforme resultados detalhados a seguir. 
Figura 3: Score dos participantes (\%)

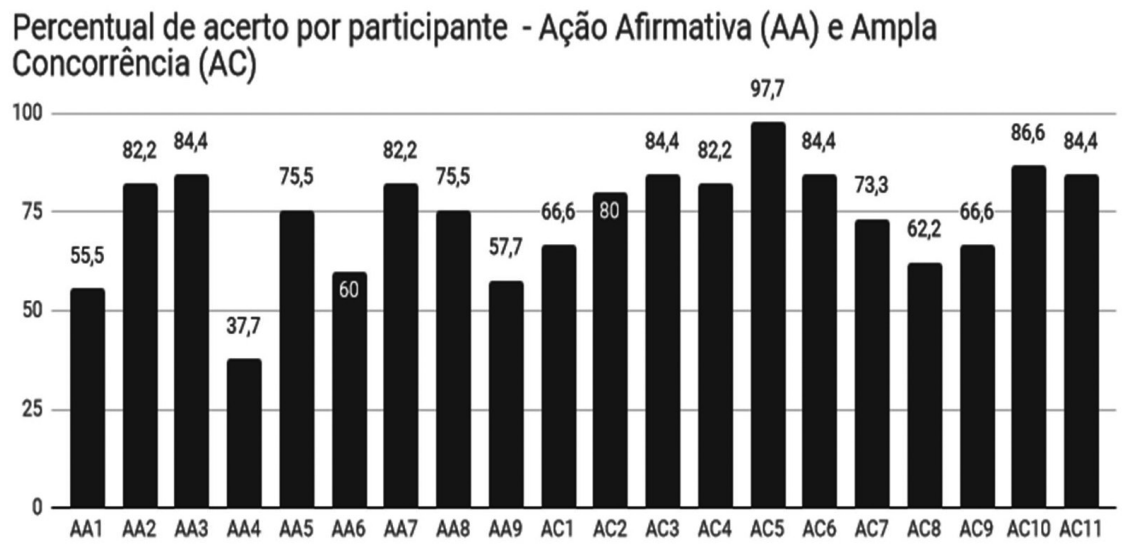

Tabela 1: Resultado dos alunos ingressantes pelo sistema de ações afirmativas nas palavras de conteúdo

\begin{tabular}{|c|c|}
\hline \multicolumn{2}{|c|}{$\begin{array}{c}\text { Resultado por participante } \\
\text { (\% de acerto) }\end{array}$} \\
\hline AA1 & 64,5 \\
\hline AA2 & 83,8 \\
\hline AA3 & 80,6 \\
\hline AA4 & 32,2 \\
\hline AA5 & 77,4 \\
\hline AA6 & 54,8 \\
\hline AA7 & 80,6 \\
\hline AA8 & 74,1 \\
\hline AA9 & 67,7 \\
\hline
\end{tabular}


Tabela 2: Resultado dos alunos ingressantes pelo sistema de ações afirmativas nas palavras funcionais

\begin{tabular}{|c|c|}
\hline \multicolumn{2}{|c|}{$\begin{array}{c}\text { Resultado por participante } \\
\text { (\% de acerto) }\end{array}$} \\
\hline $\mathrm{AA} 1$ & 35,7 \\
\hline $\mathrm{AA} 2$ & 78,5 \\
\hline $\mathrm{AA} 3$ & 92,8 \\
\hline $\mathrm{AA} 4$ & 50 \\
\hline $\mathrm{AA} 5$ & 71,4 \\
\hline $\mathrm{AA} 6$ & 71,4 \\
\hline $\mathrm{AA} 7$ & 85,7 \\
\hline $\mathrm{AA} 8$ & 78,5 \\
\hline $\mathrm{AA} 9$ & 35,7 \\
\hline
\end{tabular}

Tabela 3: Resultado dos alunos ingressantes por ampla concorrência nas palavras de conteúdo

\begin{tabular}{|c|c|}
\hline \multicolumn{2}{|c|}{$\begin{array}{c}\text { Resultado por participante } \\
\text { (\% de acerto) }\end{array}$} \\
\hline AC1 & 64,5 \\
\hline AC2 & 80,6 \\
\hline AC3 & 90,3 \\
\hline AC4 & 87,1 \\
\hline AC5 & 96,7 \\
\hline AC6 & 84,4 \\
\hline AC7 & 67,7 \\
\hline AC8 & 91,3 \\
\hline AC9 & 67,7 \\
\hline AC10 & 90,3 \\
\hline AC11 & 83,8 \\
\hline
\end{tabular}


Tabela 4: Resultado dos alunos ingressantes por ampla concorrência nas palavras funcionais

\begin{tabular}{|c|c|}
\hline $\begin{array}{c}\text { Resultado por participante } \\
\text { (\% de acerto) }\end{array}$ \\
\hline AC1 & 71,4 \\
\hline AC2 & 78,5 \\
\hline AC3 & 71,4 \\
\hline AC4 & 71,4 \\
\hline AC5 & 100 \\
\hline AC6 & 100 \\
\hline$A C 7$ & 85,7 \\
\hline$A C 8$ & 64,2 \\
\hline$A C 9$ & 64,2 \\
\hline$A C 10$ & 78,5 \\
\hline AC11 & 85,7 \\
\hline
\end{tabular}

A diferença significativa entre ingressantes pelo sistema de ações afirmativas e ingressantes por ampla concorrência, $67,85 \%$ de média simples dos acertos contra $78,94 \%$, sugere que o grupo ingressante por ação afirmativa realmente precisa de uma atenção especial no que se refere às habilidades de leitura.

Paralelamente, entre todos os participantes, tivemos apenas um resultado acima de 90\% de acerto, demonstrando que a maioria dos participantes não conseguiu obter uma nota elevada. Cabe ressaltar que esse participante que obteve nota superior a 90\% está em sua segunda graduação, sugerindo que a passagem pela universidade pode ter sido um fator crucial para o desenvolvimento das habilidades de leitura do indivíduo.

Quanto à variável tipo de item, temos uma média simples de $75,3 \%$ para as palavras de conteúdo, dentre todos os participantes e $72,8 \%$ para as palavras funcionais. Contrariando nossa expectativa de que o resultado seria superior nas palavras funcionais, o resultado sugere que não há distinção entre o desempenho nas palavras de conteúdo e funcionais. 


\section{Próximos Estudos}

A partir da observação dos resultados dos testes aplicados aos alunos do $1^{\circ}$ período do curso de Letras da Universidade Federal Fluminense, percebemos que ainda temos um longo caminho pela frente no que se refere à qualidade do ensino básico, em especial nas áreas de leitura e escrita.

A ideia é que possamos, a partir desse primeiro estudo, dar continuidade à proposta e realizar um estudo longitudinal com esses mesmos participantes para verificar se ao final da graduação, o nível de proficiência em leitura permaneceu o mesmo ou melhorou. Da mesma forma, consideramos que seriauma contribuiçãointeressante para a educação superior aplicar o teste em outras instituições do estado do Rio de Janeiro, para que possamos entender melhor o panorama da leitura em nível universitário em nosso estado, em instituições públicas e privadas.

Com esse resultado, poderemos pensar em planos de intervenção e orientações para a elaboração de políticas públicas que possam dar conta de melhorar a qualidade do ensino superior e auxiliar os alunos em suas jornadas como leitores e futuros professores que ensinarão as próximas gerações a lerem. Ressaltamos que de nenhuma forma esses resultados devem estar a serviço de uma política contra as ações afirmativas.

Por fim, acreditamos que a Psicolinguística, estudo com uma perspectiva cognitiva sobre o processamento linguístico, tem ainda grandes contribuições a dar para a sociedade no que se refere à leitura, na medida em que as conclusões tiradas a partir de pesquisas experimentais podem - e devem - dialogar com as pesquisas pedagógicas sobre o tema no sentido de formar pessoas capazes de ler criticamente e, portanto, mais aptas a exercerem a cidadania de forma plena. 


\section{Referências}

AÇÃO EDUCATIVA; INSTITUTO PAULO MONTENEGRO. Indicador de Alfabetismo Funcional - INAF - Estudo especial sobre alfabetismo e mundo do trabalho, 2016.

ADAMS, M. J. Reading. In: R. A. Wilson, F. AA. Keil. The MIT encyclopedia of the cognitive sciences. Cambridge, MA: MIT Press, 1999.

ADELBERG, A. H.; RAZEK, J. R. The Cloze Procedure: A Methodology for Determining the Understandability of Accounting Textbooks. The Accounting Review, 1984.

ALTMANN, G. \& STEEDMAN, M. Interaction with context during human sentence processing. Cognition, 30, 191-238, 1988.

CABRAL, L. S. Processos psicolinguísticos de leitura e a criança. Porto Alegre: Letras de Hoje, v. 19, n. 1, pp. 7-20, 1986.

CARPENTER, P. A. \& JUST, M. A. What your eyes do while your mind is reading. In: K. Tayner (Ed.). Eye movements in reading: Perceptual and language processes. San Diego,CA: Academic Press., 1983.

CRAIN, S.; STEEDMAN, M. J. On not being led up the garden path: The use of context by the psychological parser. In D. DOWTY, L. KARTTUNEN \& A. ZWICKY (Eds.) Natural language parsing: Psychological computational, and theoretical perspectives. Cambridge University Press, 1984.

FOUCAMBERT, J. A leitura em questão. Porto Alegre: Artes Médicas. 1994.

GARROD, S.; DANEMAN, M. Reading, psychology of. In: Encyclopedia of cognitive science. Vol.3. Londres: Nature Publishing Group, 2003.

HAYHOE, M. M. Advances in relating eye movements and cognition. Infancy, v. 6, p. 267-274, 2004.

IBOPE. $3^{\circ}$ Indicador Nacional de Alfabetização Funcional. São Paulo, 2003. 
INEP. Relatório Nacional PISA 2012: Resultados Brasileiros. ISBN: 978-8563489-17-3. Disponível em: http://download.inep.gov.br/acoes_internacionais/ pisa/resultados/2014/relatorio_nacional_pisa_2012_resultados_brasileiros.pdf

INSTITUTO BRASILEIRO DE GEOGRAFIA E ESTATÍSTICA. Censo da Educação Superior, 2015. Rio de Janeiro: IBGE, 2015.

JERÔNIMO, G. O processamento da leitura e as especificidades dos hemisférios cerebrais. 2012. (Disponível em: http://online.unisc.br/seer/index.php/signo/ article/download/2980/2326, acesso em 06 abr. 2016)

KENEDY, E. O status da norma culta na língua-I dos brasileiros e seu respectivo tratamento na escola: algumas contribuições de estudos formalistas à educação. In. Linguística: Pesquisa e Ensino vol. 2. Boa Vista: EDUFRR, 2016

KLEIMAN, A. Texto eleitor: aspectos cognitivos da leitura. Campinas: Pontes, 2007.

LEFFA, Wilson. Aspectos da leitura. Porto Alegre: Sagra-DC Luzzato, 1996.

MAIA, M. Computação estrutural e de conjunto na leitura de períodos: um estudo de rastreamento ocular. IN.: MAIA, M (org). Psicolinguística e educação. SP: Mercado de Letras, 2018. pp 103-132.

MENEZES-FILHO, N. Os Determinantes do Desempenho Escolar do Brasil. Instituto Futuro Brasil, Ibmec-SP e FEA-USP. São Paulo, 2007. Disponível em: https://jornalggn.com.br/sites/default/files/documentos/desempenho_ escolar.pdf. Acesso em: 20 março 2018.

MORAIS, J. A Arte de ler. Tradução de Álvaro Lorencini. São Paulo: Editora da Universidade Estadual Paulista, 1996.

PERFETTI, C. A. Reading skills. In International encyclopedia of the social \& behavioral sciences (pp. 12800 - 12805). Oxford: Pergamon, 2001.

SCLIAR-CABRAL, L. Revendo a categoria "analfabeto funcional". Revista CrearMundos, $\mathrm{n}^{\circ} 3$ (especial) Home Índice Editorial Links "Año del libro", 2003. 
SMITH, F. Compreendendo a Leitura: Uma análise psicolinguística da leitura e do aprender a ler. $4^{\mathrm{a}}$ ed. Porto Alegre: Artmed, 2003.

STERNBERG, R. J. Psicologia cognitiva. São Paulo: Cengage Learning, 2012.

TAYLOR, W. L. Cloze procedure: A new tool for measuring readability. Journalism Quarterly, 30, 415-433, 1953.

.Cloze Readability Scoresas Indices of Individual Differencesin Comprehension and Aptitude. Journal of Applied Psychology, 1957.

\section{Como citar}

SOUZA, Joana Angélica; KENEDY, Eduardo. Repensando as habilidades de leitura no ensino superior sob a ótica da psicolinguística experimental. Revista da Abralin, v. 17, n. 1, p. 334-359, 2018.

Recebido 17/10/2018 e aceito em 14/01/2019. 